\title{
Effectiveness of diabetes mellitus management program at primary health care level
}

\author{
S. T. Tazhbenova ${ }^{1}$, I. Millere ${ }^{2}$, L. S. Yermukhanova ${ }^{1}$, G. Sultanova ${ }^{1}$, M. Turebaev ${ }^{1}$, B. P. Sultanova ${ }^{3}$
}

\begin{abstract}
Annotation: Diabetes mellitus is considered not only a serious chronic disease, but also as an important medical and social problem that is becoming increasingly important. Disease management programs are needed to empower patients and help them develop the necessary skills for selfmanagement of their condition.

Objective: To evaluate the effectiveness of the Type 2 Diabetes Management Program at the primary health care level.

Methods: Study design is a prospective study, case-control. The study of the intervention group included 114 adults with type 2 diabetes participating in the Disease Management Program and the control group - 60 adults with type 2 diabetes not participating in the Disease Management Program. All the investigated persons live in the service area of the municipal polyclinic No. 4 of Aktobe city (Aktobe region, Western region of Kazakhstan). A traditional care which included regular follow-ups every 3 months was provided in the control group. The selection of patients in the control group was carried out by random sampling. Both groups were randomized by age, gender, and duration of illness. The main result evaluated glycated hemoglobin levels, blood pressure, body mass index, and low density lipoprotein levels after 9 months.

Results: According to the data obtained after 9 months of the study the analysis showed a decrease in the average level of glycated hemoglobin in the intervention group $(7.8 \pm 1.5 \%)$ compared with the control group ( $8.6 \pm 1.8 \%)(p<0.05)$. And also in the intervention group $(134.6 \pm 12.5$ and 83.3 \pm 6.5 ) compared with the control group (125.7 \pm 10.4 and $80.7 \pm 6.2$ ), systolic and diastolic blood pressure is shown below. There were no statistically significant differences between the groups according to body mass index and low-density lipoprotein.

Findings: This Diabetes Management Program allows you to control such indicators as glycated hemoglobin and blood pressure in a positive direction. While both body mass index and low density lipoproteins remained at the same level due to the short observation time.
\end{abstract}

Keywords: diabetes, self-management, disease management program

\section{INTRODUCTION}

Diabetes mellitus is an important medical and social problem in the world and the Republic of Kazakhstan due to the widespread prevalence and steady growth of the incidence rate (1). In Kazakhstan, according to the National Register for 2018, 326,449 patients with this diagnosis were registered. Over 10 years the number of people suffering from diabetes in our country has more than doubled (18). According to WHO (World Health Organization) data in 2017422 million or $8.5 \%$ of the world's adult population aged 18 years and over live with diabetes (18). According to the International Diabetes Federation (IDF) in 2017, 425 million (8.8\%) of the adult population in the world suffer from type 2 diabetes. About $80 \%$ of diabetic patients live in low- and middle-income countries $(7,14)$. About 4 million people die of diabetes every year in the world, every 10 seconds 1 person dies from a diabetes-related disease. At present, diabetes mellitus takes the third place due to death among chronic noncommunicable diseases (19). And today diabetes remains one of the most urgent problems of modern health care, being the leading causes of high premature mortality and disability in developed countries.

The goal of the Disease Management Program is to change the mentality of medical workers and a patient, create partnerships, involve patients in managing their personal health with the creation of a patient-oriented model to improve the health and quality of life of patients, reduce clinical complications, mortality and disability in chronic noncommunicable diseases $(4,17)$. Few data available in Kazakhstan indicate favorable outcomes of this program, but they

\footnotetext{
1 West Kazakhstan State Medical University, Aktobe, Kazakhstan.

2 Riga Stradins University, Riga, Latvia.

3 Al Farabi Kazakh National University, Almaty, Kazakhstan.
}

Correspondence: S. T. Tazhbenova

West Kazakhstan State Medical University, Aktobe, Kazakhstan.

Received: 9 Jul 2019, Accepted: 30 Oct 2019

(C) 2019 by the authors; licensee Modestum Ltd., UK. This article is an open access article distributed under the terms and conditions of the Creative Commons Attribution License (http://creativecommons.org/licenses/by/4.0/). 


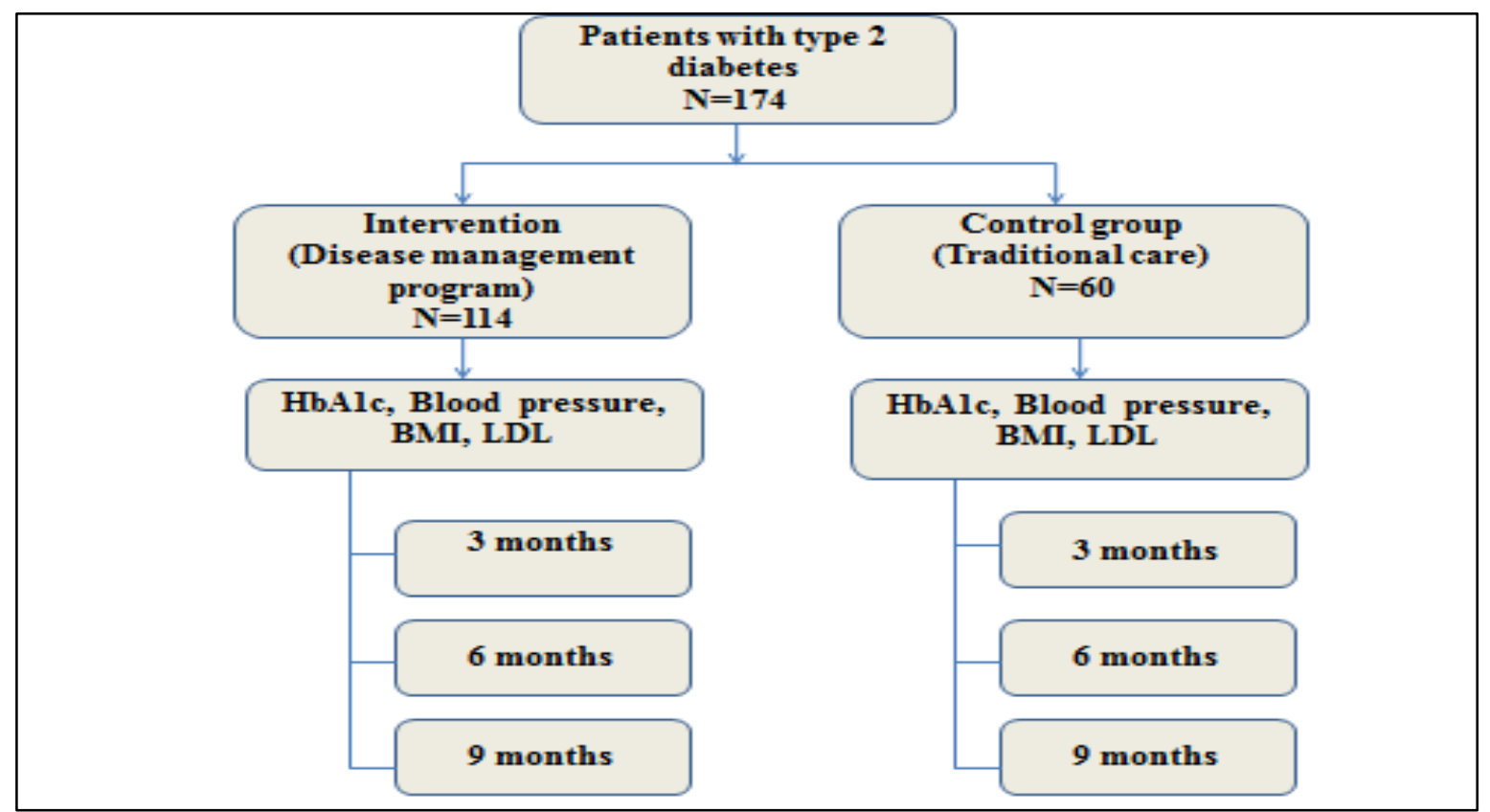

Figure 1: Study design

HbA1c: Glycated haemoglobin; BMI: body mass index; LDL: low density lipoproteins

have not yet been evaluated using prospective studies and have not been compared with traditional treatment. And this served as the basis for conducting studies to evaluate the effectiveness of the disease management program in our conditions.

The purpose of this study was to evaluate the effectiveness of the Type 2 Diabetes Management Program compared to traditional care at the primary health care level.

\section{METHODS}

\section{Study Design - Prospective Study, Case-Control}

The study was conducted in the conditions of the municipal polyclinic №4 of Aktobe city (Aktobe region, Western region of Kazakhstan). This is a prospective case-control study in primary care with randomization at the practice level. The groups were divided into the main groups (Diabetes Management Program) and the control group (traditional care).

The main criteria for inclusion in the study were patients over the age of 18 and with type 2 diabetes mellitus, exclusion criteria were children and adolescents and patients with type 1 diabetes mellitus. All participants signed an informed consent. The study in the intervention group included 114 adults with type 2 diabetes participating in the Disease Management Program and in the control group there were 60 adults with type 2 diabetes not participating in the Disease Management Program. The selection of patients in the control group was carried out by random sampling. Both groups are randomized by age, gender, and duration of illness. The main result evaluated glycated hemoglobin levels, blood pressure, body mass index, and low density lipoprotein levels after 9 months. The studies were conducted on routine three-month appointments. This approach was used to minimize research costs and reduce the burden on patients.

\section{STATISTICAL ANALYSIS}

We used descriptive statistics. Continuous variables were expressed as mean and standard deviation; categorical variables were expressed as numbers and percentages. To evaluate the effectiveness of the program the data were analyzed and comparative statistics were made between the main parameters of the intervention group and the control group. To test the hypothesis of a normal distribution, the Shapiro-Wilk test was used. The marked criteria were significant at $p<0.05$. Statistical analysis and data processing was performed using software $R v$ 3.5.1.

\section{RESULTS}

According to the results of the study the average age of patients with diabetes participating in the disease management program was $56.5 \pm 8.1$ years, and the average age of patients in the control group was $58 \pm 8.8$ years. Of the participants in the study group, men accounted for $49 \%$, women $51 \%$, and in the control group men $-45 \%$, women 
Table 1: Baseline characteristics of participants, by study group

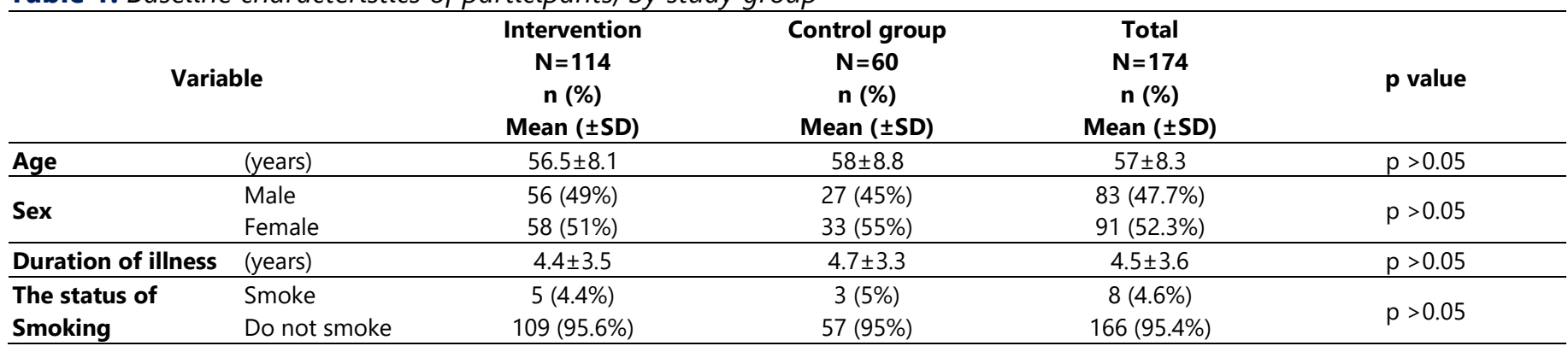

Table 2: Average values in the intervention group and the control group after 9 months

\begin{tabular}{lccc}
\hline Variable & $\begin{array}{c}\text { Intervention } \\
\mathbf{N}=\mathbf{1 1 4} \\
\text { Mean }( \pm \mathbf{S D})\end{array}$ & $\begin{array}{c}\text { Control group } \\
\mathbf{N = 6 0} \\
\text { Mean }( \pm \mathbf{S D})\end{array}$ & p value \\
\hline Body mass index $\left(\mathrm{kg} / \mathrm{m}^{2}\right)$ & $31 \pm 5.1$ & $32 \pm 4.7$ & $\mathrm{p}>0.05$ \\
\hline Systolic blood pressure $(\mathrm{mmHg})$ & $125.7 \pm 10.4$ & $134.6 \pm 12.5$ & $\mathbf{p}<\mathbf{0 . 0 5}$ \\
\hline Diastolic blood pressure $(\mathrm{mmHg})$ & $80.7 \pm 6.2$ & $83.3 \pm 6.5$ & $\mathbf{p}<\mathbf{0 . 0 5}$ \\
\hline Low density lipoproteins $(\mathrm{mg} / \mathrm{dL})$ & $3.5 \pm 1.1$ & $3.7 \pm 0.9$ & $\mathrm{p}>0.05$ \\
\hline Glycated haemoglobin $(\mathrm{HbA} \mathrm{C})(\%)$ & $7.8 \pm 1.5$ & $8.6 \pm 1.8$ & $\mathbf{p}<\mathbf{0 . 0 5}$ \\
\hline
\end{tabular}

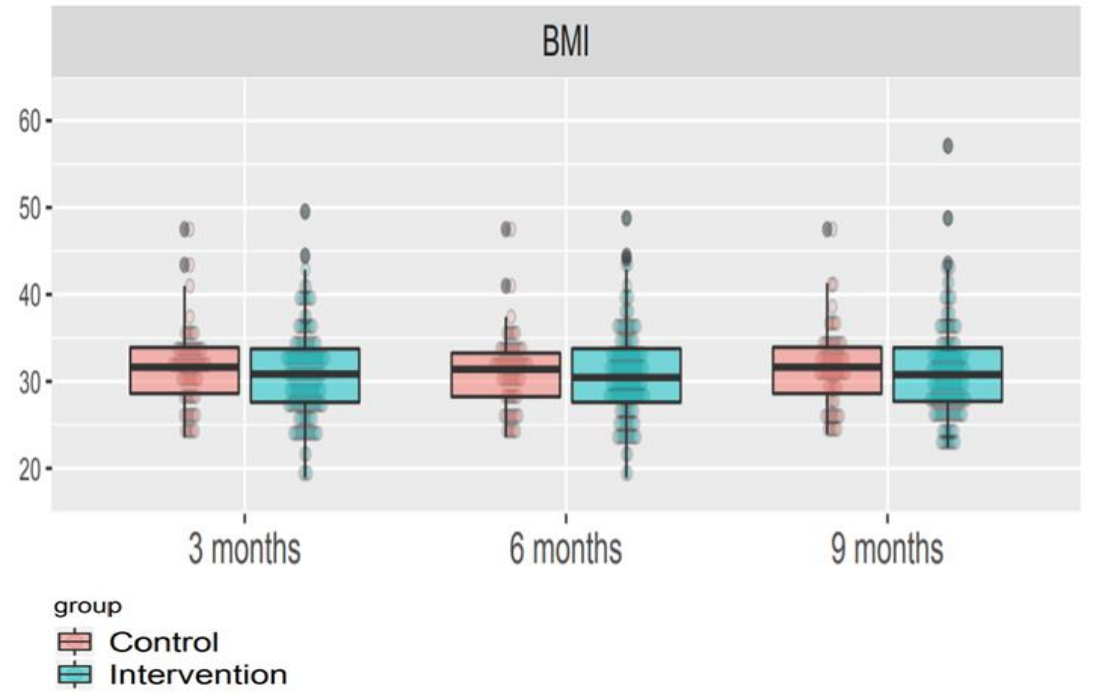

Figure 2: The level of BMI in the intervention group and the control group after 3, 6 and 9 months $\left(\mathrm{kg} / \mathrm{m}^{2}\right)$

- 55\%. In the experimental group the duration of the disease with type 2 diabetes mellitus was $4.4 \pm 3.5$ years and in the control group it was $4.7 \pm 3.3$ years (Table 1 ).

Both groups were the same in terms of age, gender, smoking status, and the use of sugar-lowering drugs (BSC, all drugs except insulin). There were no statistically significant differences between the groups $(p<0.05)$.

In patients with diabetes mellitus participating in the disease management program and not participating in the BMI program (body mass index) after 9 months it was $31 \pm 5.1$, in the control group $32 \pm 4.7$ (Table 2). There were no statistically significant differences between the groups according to BMI (body mass index) ( $p>0.05$ ) (Figure 2).

The level of systolic blood pressure in patients with diabetes mellitus participating in the Disease Management Program after 9 months was $125.6 \pm 10.4 \mathrm{~mm} \mathrm{Hg}$, in the control group not participating in the program - $134.6 \pm 12.5$ $\mathrm{mm} \mathrm{Hg}$ and in the intervention group diastolic blood pressure was $80.7 \pm 6.2 \mathrm{~mm} \mathrm{Hg}$, while in the control group it was $83.3 \pm 6.5 \mathrm{~mm} \mathrm{Hg}$ (Table 2). The level of systolic and diastolic pressure in patients with diabetes mellitus participating in the Disease Management Program was lower than in patients with diabetes mellitus not participating in the Disease Management Program. There are statistically significant differences between groups in blood pressure $(p<0.05)$ (Figure 3). 


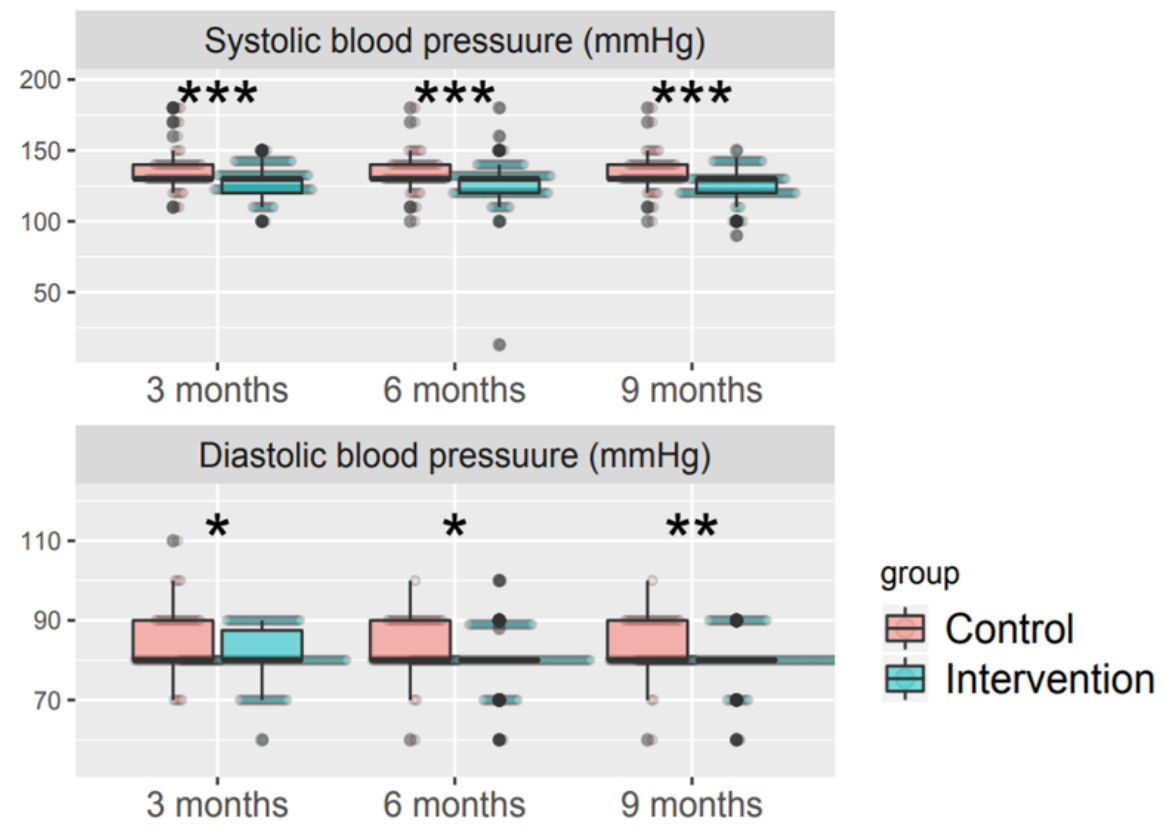

Figure 3: The level of systolic and diastolic blood pressure in the intervention group and the control group after 3, 6 and 9 months $(\mathrm{mmHg})$

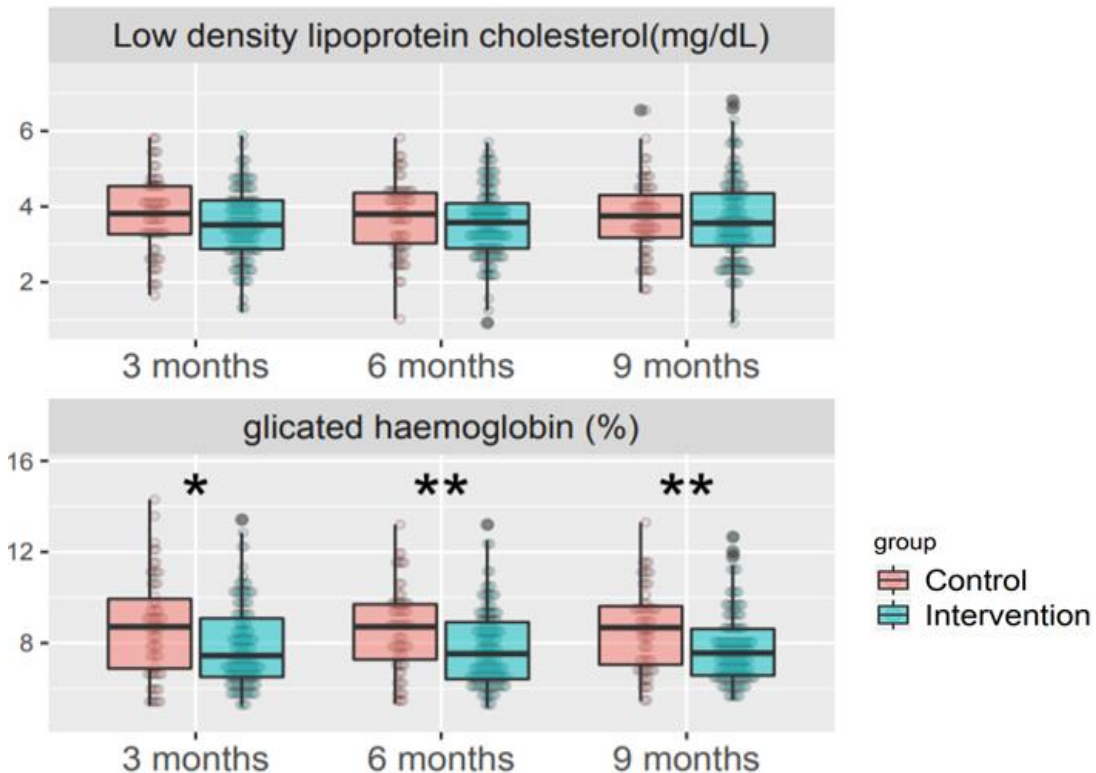

Figure 4: The level of low density liproteincholesterol $(\mathrm{mg} / \mathrm{dL})$ and glycated hemoglobin in the intervention group and the control group after 3, 6 and 9 months (\%)

Glycated hemoglobin has been widely used in studies of diabetes mellitus (11), in particular, to assess the effectiveness of diabetes management $(12,13,15)$.

The study also analyzed laboratory analyzes of patients, the average levels of glycated hemoglobin (HbA1c) in the control group after 9 months was $8.6 \pm 1.8 \%$, in the intervention group $7.8 \pm 1.5 \%$ (Table 2). The analysis showed a decrease in the average level of glycated hemoglobin in the intervention group compared with the control group after 9 months $(p<0.05)$.

The average levels of LDL cholesterol (low density lipoproteins) in the intervention group $3.5 \pm 1.1 \mathrm{mmol} / \mathrm{L}$ were higher than in the control group $3.7 \pm 0.9 \mathrm{mmol} / \mathrm{L}$ (Table 2). There were no statistically significant differences between the groups according to LDL (low density lipoproteins) ( $p>0.05$ ) (Figure 4).

There were no significant differences between the intervention group and the control group according to baseline characteristics after 3, 6 and 9 months. 


\section{DISCUSSION}

One of the most promising directions in the prevention and treatment of patients with diabetes mellitus and in achieving control over the main manifestations of diseases is the training of patients in self-control and self-help skills (16). The self-government program is an important basic approach to empowering and necessary for patients to effectively manage their behavior, including controlling blood glucose levels, managing hyperglycemia and hypoglycemia symptoms, controlling diet and exercise management $(5,6)$. However, mainly patients with diabetes have difficulty controlling their behavior (8). The self-government program is promoted in connection with positive results, especially in managing behavior and improving the quality of life among patients with type 2 diabetes (9).

Our analysis of thereferences shows positive effects for groups of patients participating in the Disease Management Program in comparison with non-participating patients. Studies in the United States have shown that participating in a self-management program improves the outcomes of patients who have already received diabetes education (10).

In Germany, a disease management program was introduced more than 10 years ago. The data from the German disease management program for type 2 diabetes mellitus demonstrate an improvement in the quality of treatment in relation to pharmacotherapy and patient education and, therefore, more stringent adherence to guidelines. However, no significant improvement was observed with respect to smoking status, obesity or control of HbA1c (glycated hemoglobin) (2).

In India, the results of the study showed that the self-management education program is an important component in diabetes management and provided concrete evidence that it is an effective way of controlling body weight, blood pressure and glycated hemoglobin level in type 2 diabetes mellitus (3).

Based on the results of our study we also studied the effectiveness of Type 2 Diabetes Management Program, compared to traditional conventional care at the primary health care level. This study is one of the first studies in Kazakhstan to evaluate the intervention carried out in primary health care facilities to improve health outcomes in a group of patients not participating in the Type 2 Diabetes Disease Management Program. After a 9-month follow-up in the intervention group for patients with type 2 diabetes mellitus, a decrease in glycated hemoglobin and blood pressure was observed compared with the control group. Type 2 diabetes management program has had a positive effect on changes in glycated hemoglobin and blood pressure. There were no statistically significant differences between the groups according to body mass index and low-density lipoproid. This also confirms the effectiveness of the program being studied.

\section{CONCLUSION}

This Diabetes Management Disease Management Program allows you to control for the study such indicators as glycated hemoglobin and blood pressure in a positive direction. When both the body mass index and low density lipoproteins remained at the same level due to the short observation time.

\section{REFERENCES}

1. Tazhbenova S, Yermukhanova L, Artykbayeva M, Kuspangalieva G. Prevalence of diabetes in the world and in the republic of Kazakhstan. Astana Medical Journal, 2018;4(98):21-32.

2. Mehring $M$, Donnachie $E$, Bonke FC, Werner $C$, Schneider A. Disease management programs for patients with type 2 diabetes mellitus in Germany: a longitudinal population-based descriptive study. Diabetol Metab Syndr., 2017;9:91-4. https://doi.org/10.1186/s13098-017-0236-y PMid:28529546 PMCid:PMC5437566

3. Khunti K, Gray L, Skinner T, Carey ME, Realf K, Dallosso H, Fisher H, Campbell M, Heller S, Davies MJ. Effectiveness of a diabetes education and self management programme (DESMOND) for people with newly diagnosed type 2 diabetes mellitus: three year follow-up of a cluster randomised controlled trial in primary care, BMJ: British Medical Journal (Overseas \& Retired Doctors Edition), 2012;344(7860):15. https://doi.org/10.1136/bmj.e2333 PMid:22539172 PMCid:PMC3339877

4. Aktaeva LM, Garkalov KA, Kulkaeva GU. Implementation of disease management programs in practical health care: Guidelines. Astana, 2013:39.

5. Shu-Fang VW, Shu-Yuan L, Tsae-Jyy W, Mei-Hui C, Yu-Mei J, Kuei-Chen C. Self-management intervention to improve quality of life and psychosocial impact for people with type 2 diabetes. J Clin Nurs., 2014;20(17-18):265565. https://doi.org/10.1111/j.1365-2702.2010.03694.x PMid:21605212 
6. Pranee $\mathrm{CL}$, Supunnee T. Diabetes type 2 self-management among Thai Muslim women. J of Nurs and Health Care of Chro Illness, 2011;3(1):52-60. https://doi.org/10.1111/j.1752-9824.2011.01079.x

7. International Diabetes Federation. IDF Diabetes Atlas. 8th ed. Brussels, Belgium: International Diabetes Federation; 2017.

8. Chiu-Cu L, Robert MA, Chao-Sung, C, Bonnie MH, Charol JL. Development and testing of the diabetes selfmanagement instrument: a confirmatory analysis. Research in Nurs \& Health, 2008;31(4):370-80. https://doi.org/10.1002/nur.20258 PMid:18213627

9. Rian AP, Tippamas $C$, Charuwan $\mathrm{K}$. The effect of dietary and exercise self management support program on dietary behavior, exercise behavior and clinical outcomes in Muslim patients with poorly controlled type 2 DM in a community setting in Indonesia. NurseMdia Journal of Nursing, 2015:5-14. https://doi.org/10.14710/nmjn.v5i1.10186

10. McGowan P. The efficacy of diabetes patient education and self-management education in type 2 diabetes. Can J Diab, 2011;35:46e53. https://doi.org/10.1016/S1499-2671(11)51008-1

11. WHO Guidelines Approved by the Guidelines Review Committee, Use of Glycated Haemoglobin (HbA1c) in the Diagnosis of Diabetes Mellitus: Abbreviated Report of a WHO Consultation World Health Organization, Geneva (2011)

12. Patil SJ, Ruppar T, Koopman RJ, et al. Peer support interventions for adults with diabetes: a meta-analysis of hemoglobin A1c outcomes, Ann. Fam. Med., 2016;14(6):540-51. https://doi.org/10.1370/afm.1982 PMid:28376441 PMCid:PMC5389404

13. Zhang $X$, Yang $S$, Sun $K$, et al. How to achieve better effect of peer support among adults with type 2 diabetes: a meta-analysis of randomized clinical trials. Patient Educ. Couns., 2016;99(2):186-97. https://doi.org/10.1016/j.pec.2015.09.006 PMid:26463156

14. Cho NH, Shaw JE, Karuranga S, Huang Y, Rocha Fernandes JD, Ohlrogge AW, Malanda B. IDF Diabetes Atlas: Global estimates of diabetes prevalence for 2017 and projections for 2045. Diabetes research and clinical practice, 2018;(138):271-81. https://doi.org/10.1016/j.diabres.2018.02.023 PMid:29496507

15. Dale JR, Williams SM, Bowyer V. What is the effect of peer support on diabetes outcomes in adults? A systematic review. Diabet. Med., 2012;29(11):1361-77. https://doi.org/10.1111/j.1464-5491.2012.03749.x PMid:22804713

16. Busse R, Blümel M, Scheller-Kreinsen $D$, Zentner A. Tackling chronic disease in Europe: Strategies, interventions and challenges. Observatory Studies Series - Copenhagen: World Health Organization on behalf of the European Observatory on Health Systems and Policies, 2010;20:88-96.

17. Tlemisov VB, Zhumagulov TT, Kurmanbaeva KJ. Disease management program for three nosologies (hypertension, diabetes, chronic heart failure). Health Manager of the Republic of Kazakhstan, 2016;3-4.

18. https://www.voxpopuli.kz

19. https://www.who.int

\author{
$\diamond \diamond \diamond \diamond \diamond \diamond \diamond$ \\ http://www.ejgm.co.uk
}

